\title{
How EU-funded Smart City experiments influence modes of planning for mobility: observations from Hamburg
}

Philipp Späth ${ }^{1^{*}}$ (D) and Jörg Knieling ${ }^{2}$

\author{
* Correspondence: spaeth@envgov. \\ uni-freiburg.de \\ ${ }^{1}$ Institute for Environmental Social \\ Sciences and Geography, \\ Albert-Ludwigs-University, Freiburg, \\ Germany \\ Full list of author information is \\ available at the end of the article
}

\begin{abstract}
Hamburg participates in the EU-funded research and development project mySMARTlife (mSL) with experiments involving smart city technologies, among others in the field of transportation infrastructure. These experiments are shaped by a public-private consortium in accordance with a call of the EU research and innovation program "Horizon 2020". They focus on close to the market technologies.

The experiments aim at citizen participation. Yet, what technologies are experimented with has been decided and contractually fixed by the consortium beforehand. We explore tensions in this kind of setup, and how entrenched approaches to planning of transportation infrastructure are challenged by new subjectivities, expectations, standards and procedures. From our perspective, it is highly questionable whether a purely expert driven process can produce outcomes that sufficiently reflects local residents' ideas of sustainable and appropriate changes to urban infrastructures. For this reason, candidate 'solutions' for future mobility demands should be exposed to societal deliberation at an earlier stage in their development.

Our exploration of (possible) interplays between such an experimental approach to the shaping of infrastructures and the pre-existing integrated approach to planning has been a modest first step, and more empirical research would be needed to draw solid conclusions. It seems worthwhile to analyse more deeply the in- and exclusiveness of the actor constellations in such processes, the role of coincidences or strategies behind the selection of partners, and a possible gate-keeper function of the process initiator.
\end{abstract}

Keywords: Smart city, Experimental governance, Integrated transportation planning, EU horizon 2020 program, Urban transformation, Multi-level governance

\section{Science highlights}

- Case study on the EU project my SMARTlife exploring experiments with smart city technology in Hamburg.

- Identifies tensions between entrenched approaches to transportation planning and experimentation driven by research policy.

- Analyzes changes in subjectivities, expectations, standards and procedures.

(c) The Author(s). 2020 Open Access This article is distributed under the terms of the Creative Commons Attribution 4.0 International License (http://creativecommons.org/licenses/by/4.0/), which permits unrestricted use, distribution, and reproduction in any medium, provided you give appropriate credit to the original author(s) and the source, provide a link to the Creative Commons license, and indicate if changes were made. The Creative Commons Public Domain Dedication waiver (http://creativecommons.org/ publicdomain/zero/1.0/) applies to the data made available in this article, unless otherwise stated. 
- Understands Smart City experiments as interplay of a global discourse with local planning cultures.

- Explores potential implications for systemic urban transformation.

\section{Policy and practice recommendations}

- Candidate 'solutions' for future mobility demands should be exposed to societal deliberation at an early stage of development.

- EU-funded R\&D projects should be more solidly legitimized by early involvement of democratic bodies and procedures.

- EU-funded R\&D projects should stay open to modifications during the research process to avoid shallow (pseudo) participation.

- Technological transformation for smart mobility should integrate social and cultural knowledge to achieve user-driven solutions and avoid governance-failure.

- Funding regulations should prescribe transparent, open processes for the selection of partners and 'solutions' into project consortia.

\section{Introduction}

The 'Smart City' has gained increasing prominence in debates about visions and guidelines for urban development (de Jong et al., 2015, Mora et al., 2017, Karvonen et al., 2019). The concept is often used to suggest that newly available digital technologies enable new ways to shape or even control urban development. To exploit these opportunities, many local governments have committed to establish ICT infrastructures that often link different sectors and are meant to enable more efficiency in service provision as well as the provision of new services (Goldsmith \& Crawford 2014, Townsend 2013; Karvonen et al., 2019:1).

In one strand of literature, Smart City initiatives are characterized as highly influential "corporate story telling", marked by "technocratic reductionism and the introduction of new moral imperatives in urban management" (Söderström et al., 2014:307). From this perspective, key institutions of local planning appear to be strongly influenced by the globally present ideal of the smart city. Contrastingly, Cugurullo (2018) observes, that the "grand visions" of the smart city and eco-city are in some cases only superficially binding projects together. Instead of "advancing a holistic and rigorous method of city-making, as claimed by their advocates, they are reproposing traditional chaotic urban models which have been around for milleninia" (Cugurullo 2018: 87) According to his observations in cases like Hong Kong and Masdar City, any claims that infrastructural development was decided upon in comprehensive and systematic processes of planning are highly questionable.

However, after looking at some British cases of Smart Cities, Cowley and Caprotti (2018) describe these initiatives not as pretending, but as "anti-planning". They observe "a body of practices emerging at the local level, typically located only at the fringes of mainstream institutional power" (ibid.2) and therefore explore "the possibility that the smart city challenges, rather than merely enhances, more conventional planning and policy mechanisms" (ibid.). Although they assess effects of smart city initiatives in different spheres, all these authors call attention to observable impacts that smart city narratives have on place-bound practices of planning. They also discuss cases of smart city 
governance as reflections of a broader trend towards "experimental" urban governance. While Cugurullo (2018) highlights obvious contrasts between the factual developments in smart cities and the ideal of systematic and comprehensive experimentation, Cowley and Caprotti (2018) are concerned by a somewhat opposite trend: "in valorising pragmatic learning over predefined long-term outcomes, smart city experimentation performatively excludes a structural understanding of social and environmental problems." (ibid.:15).

We can substantiate this latter concern by analysing an "actually existing Smart City" (Shelton et al., 2015) in the form of the EU funded Smart City "lighthouse" activities in Hamburg, Germany. In particular, we study influences that an EU smart city agenda, and here especially the requirements of a dedicated call for proposals within the Horizon 2020 funding scheme, ${ }^{1}$ can have on local practices of transportation planning in Hamburg. ${ }^{2}$

Within the Horizon 2020 program, the European Smart Cities and Communities (SCC) competitive calls motivated many European consortia of municipalities, technology providers, researchers and consultants to join around the idea of "lighthouse cities" that drive a market development for Smart City technologies and set examples for other cities to learn from. The specific call asked for "research and full-scale testing" of solutions for "reducing energy consumption and carbon footprint by smart and sustainable use". ${ }^{3}$ It was embedded in a program that strongly promoted public-private partnerships in urban infrastructures, experimentation and "smart governance". What we observe in the context of these competitions, hence, is a new and very particular approach to planning of urban infrastructures - or, rather, to directly shaping them in ways that actually challenge various principles of entrenched planning approaches.

Within one such SCC project, called "mySMARTLife" (mSL), three local consortia consisting of urban governments, technology and service providers, researchers and facilitators implement "experiments" in the fields of energy, building, mobility, and governance - including some significant investments - in Hamburg, Helsinki and Nantes. We argue, and aim to illustrate, that, for example in mobility, this project's "experimental" approach to shaping urban infrastructures (and the intended creation of markets for smart technologies) is challenging longstanding principles and practices of planning. In Hamburg, for example, the city-state administration has explicated its approach to "integrated transportation planning" in its Mobility Program of 2013, i.e. just before the city got engaged in international Smart City consortia. This provides an opportunity, to juxtapose the characteristics of the smart city "experiments" in mobility with the characteristics of the entrenched planning approach.

\footnotetext{
${ }^{1}$ As advocated on the EU commissions' website, "Horizon 2020 is the financial instrument implementing the Innovation Union, a Europe 2020 flagship initiative aimed at securing Europe's global competitiveness". Nearly $€ 80$ billion of funding have been made available for research and innovation in the years 2014-2020 "as a means to drive economic growth and create jobs". https://ec.europa.eu/programmes/horizon2020/whathorizon-2020

${ }^{2}$ We are aware of the different paradigms associated with the terms "mobility planning" vs. "transportation planning". In Hamburg, most actors usually refer to "transportation planning" (Verkehrsplanung), while in 2013, the programmatic document promoting "integrated transportation planning" has been called "mobility program" (Mobilitätsprogramm). For consistency within this contribution, we refer to "transportation planning" throughout, except for those cases, where explicit reference has been made to "mobility" in situ. ${ }^{3}$ https://cordis.europa.eu/programme/rcn/664323/en
} 
In this contribution, we hence examine a particular interplay of EU funded smart city activities, that we consider to form part of a "global discourse network" (Joss et al., 2019, building on Khor 2016) with locally entrenched principles of transportation planning.

The following two research questions are guiding our analysis:

A) What conceptual models and value orientations for urban change underpin the "experimental" shaping of transportation infrastructure in Hamburg's mySMARTlife activities? And how do they match with the entrenched approach of Integrative transportation planning in Hamburg?

B) How does the interplay of Smart City experiments with the entrenched approach to integrative transportation planning effect prospects for transformative urban change and sustainability?

The following section 2 conceptualizes Smart City activities as a particular form of experimental governance. Section 3 briefly describes the methodological approach and empirical basis of this contribution. Section 4 descriptively introduces the two elements of the case study: mSL Smart City experiments on one hand, and the approach to integrated transportation planning that had been entrenched in Hamburg before the smart city activities started. The sections 5 and 6 are devoted to answering the above mentioned research questions respectively. The final section 7 combines a discussion of our findings in light of the literature on sustainability transitions with some conclusions, including implications for research and for policies on multiple governance levels.

\section{The shaping of transportation infrastructure through Smart City experiments}

In order to understand the challenge that Smart City "experiments" can pose to planning approaches, we conceptualize the former as a specific type of experimental governance. In the early days of this literature, Bulkeley and Castán Broto (2012) found, that "experiments serve to create new forms of political space within the city, as public and private authority blur, and are primarily enacted through forms of technical intervention in infrastructure networks" (2012:361). Evans et al. (2016:2) later observed that "[e]xperimentation forms a common thread running through otherwise disparate contemporary urban trends, from corporatised attempts to create smart, low carbon cities to grassroots civic movements to make neighbourhoods more socially cohesive". "The promise of learning, and by extension innovation, lends experimentation considerable rhetorical power as a method through which to scale up from individual examples." (2016:3) This leads these authors to ask about "the politics of experimentation, or more specifically who is allowed to take part at both the institutional and practical levels". "In reframing urban development", they conclude, "experimentation shifts the balance of power between actors, empowering some while disempowering others, and privileging new forms of knowledge and evidence in the process" (2016:3). What long-term effects of such power shifts may have cannot be generally assumed but needs to be studied empirically in an open ended manner. As already (Bulkeley and Castán Broto, 2012: 267) had warned, "[r]ather than creating protected spaces through which innovation can be fostered and system change developed, experiments could provide grist in the 
urban mill, creating conflict, sparking controversy, offering the basis for contested new regimes of practice."

Savini \& Bertolini recently developed "a conceptual framework that can help problematize the relationship between experimentation and systemic change in urban policy-making and planning" (2019:832). Similarly to Bulkeley \& Castan Broto, they emphasise "that experimental agency entails a set of political biases and normative assumptions that deserve to be problematized". Understanding both social practices and regulatory and physical environments as outcomes of a 'co-evolutionary' process, they try to unpack processes in which "niches" are constructed "as institutional spaces or episodes wherein social practices generate opportunities for disruption in their regulatory and physical context" (ibid.:833) The politics around such niches are not exclusively characterized by the wish of powerful actors to either allow for variation or to suppress it, as large parts of the transition studies literature seems to assume, but can also reflect either ignorance or attempts to assimilate or marginalize such niches.

So-called Urban Living Labs (ULL), are a distinct form of experiments in urban settings that are meant to "strongly support knowledge and innovation through open and engaged learning". Kronsell \& Mukhtar-Landgren offer particular conceptual tools for "exploring 'how' municipalities act to facilitate ULL" (2018:989). The mSL activities ("interventions") in Hamburg are not explicitly called "lab", but they conceptually match the definition of a ULL in the sense that "their purpose is to initiate activities that may become future initiatives to address sustainability problems". They aim to "develop new technologies and ways of living" and they "strongly support knowledge and innovation through open and engaged learning" (ibid.: 988). The mSL interventions have the character of managed activities, are project based and thus not deduced from overall transportation planning. By doing so, they challenge and partly replace planning in a classical sense. However, they also contribute to and influence planning processes. In the context of the mSL project, for example, "deficits" in urban planning have been identified and consequentially a more thorough consideration of energy transition ambitions has been made obligatory (in the form of specific energy concepts to be included in future master plans) and supported with the development of respective "process innovations" as part of the mSL project.

Like Kronsell \& Mukhtar-Landgren we are interested in how a municipality's role in such activities is shaped by "formal rules, informal practices and structures of resources". Building on these categories and derived indicators, Kronsell \& Mukhtar develop three "ideal typical roles in experimental governance" where municipalities act primarily as "(1) promoter, (2) enabler or (3) partner" of ULL experiments (ibid.:991). "Of particular interest here is how municipalities are placed in-between a 'horizontal logic' described in terms of collaboration and network governance and a 'hierarchical logic' characterized by the formal/legal democratic framework of local government. ULL are [furthermore] examples of activities that are located in the intersection between the more 'temporary' - with its multiple and shifting actors - on the one hand, and the 'permanent' organization - on the other." (ibid.:990).

It is particularly important to ask these questions as we aim to explore what implications an interplay of such experiments with established routines of planning may have with regard to the prospects of urban sustainability transitions. The literature on experimental governance and Urban Living Labs provides valuable perspectives for an 
analysis of such interplay between an experimentation oriented approach to shaping transportation infrastructures (as represented here by the mSL Smart City lighthouse activities) and entrenched planning routines (as represented here by the integrated planning approach of the mobility program in Hamburg).

\section{Methods}

The two research questions are explored in the form of a case study on the impact EU lighthouse Smart City activities in Hamburg have on pre-existing routines and standards for transportation planning. The authors do not consider this case "critical" in the sense of Flyvbjerg (2006), as we do not see the potential for broad generalisations. But the case allows for the identification of some possible effects that an international funding mechanism can have on locally entrenched approaches to planning.

In this endeavour, the authors can build on work that they have been conducting partly as independent researchers and partly as partners within EU-Horizon 2020 consortia, as consultants to municipalities (including Hamburg) and as a member of several advisory bodies.

The case study is primarily based on an analysis of published material: policy documents like the mobility program, calls and applications for EU funding, project internal material and publications like newsletters, working papers, speech manuscripts, websites, brochures and newspaper articles. These documents where scanned for statements on how governance processes are or should be designed, in particular with regard to the planning of transportation infrastructure in Hamburg. The statements found in the context of the EU project mySMARTlife where than contrasted with those from the context of the mobility program from 2013. Further fieldwork included interviews with key experts and structured observations during project meetings. A series of 13 interviews was conducted in 2015-2017 with knowledgeable people of different backgrounds (various departments of the city administration, publically and privately owned companies, Hamburg Port Authority, civic organizations and academia). Findings from document and interview analysis were finally triangulated with experiences from participant observation in numerous project meetings and public events related directly with the mSL project or Hamburgs's Smart City activities in a broader sense.

\section{Case study: experimentation with Smart City technology versus integrated transportation planning in Hamburg}

With its roughly 1.8 million inhabitants, Hamburg is the second biggest city in Germany. The city region's territory and administration also form one of the sixteen German federal states. About 2.8 million people live in the agglomeration of Hamburg, which in turn is part of the larger "Hamburg Metropolitan Region", home to about 5.3 million people. The city encompasses the port of Hamburg in which up to 140 million tons of goods are processed annually, making it the largest harbour in Germany and the third biggest in Europe.

\section{Smart City experimentation in Hamburg - the $\mathrm{mSL}$ project}

The idea of the Smart City has first been picked up notably in Hamburg in 2011. However, it was only in 2014 that a first significant initiative was launched by the Lord 
Mayor (Spaeth et al., 2017). After the lord mayor was re-elected in 2015, the new coalition government of social democrats and now also the green party agreed on a digitalization strategy and institutionalized an officer for digitalization within its administration.

Again 1 year later, in 2016, two initiatives were developed, that aim to experiment with smart technology for Hamburg's transportation infrastructure. Both ongoing projects are clearly imbedded in (internationally shaped) Smart City agendas and are regularly mentioned as prime examples of Hamburg's ambitions to pioneer in proactive digitization: The department for economic development's initiative to develop a model Intelligent Transportation System (ITS) in Hamburg (Späth \& Knieling 2019) as well as the EU funded Smart City Lighthouse project $\mathrm{mSL}$. The latter is a five-year project (2016-2021), supported under the European Union's Horizon 2020 research and innovation programme with an overall budget of 20 mio. Euro, thereof about 6 mio. For Hamburg. After two earlier applications had failed, the city finally succeeded in 2016 in its third attempt. Twenty-eight partners from seven countries are collaborating to achieve "sustainable cities with smart people and a smart economy", to reduce $\mathrm{CO}_{2}$ emissions and to increase the use of renewable energy sources. Demonstration cities are Hamburg, Helsinki and Nantes. In Hamburg, the demonstration site is located in the district of Bergedorf with its 130,000 inhabitants, and the district administration has taken over the coordination of the activities.

Goals in the Bergedorf area are to undertake a number of Smart City experiments in the fields of housing, energy and mobility. In mobility, measures are smart adaptive lighting for bicycle roads, the installation of smart lampposts, the purchase of ten electrical buses, 40 e-cars and 50 e-bikes for public and private fleets, e-bus charging stations at the bus depot, several fast charging stations and a set of private stations for e-cars all supplied with energy stemming up to $100 \%$ from renewable energy sources. Furthermore, it is envisaged to create a multi-modal mobility concept, a car sharing ecommunity and a parcel delivery system in car trunks. Procedurally, mSL has high ambitions regarding citizen participation, which are operationalized e.g. through the setting up of an "urban platform for dialogue" and an implementation management, which aims to enable cooperative city development with the needs and expectations of its citizens in mind. If necessary, regulations and governance modes shall be adapted for the test-field areas by using the status as a model project. After an application phase of about 2 years, the project started at the end of 2016 and has reached the major implementation phase. With regard to the partial electrification of the bus fleet, for example, detailed planning and preparations have been made, including large investments in the local bus hub.

\section{Integrated transportation planning in Hamburg}

In September 2013 - i.e. before Hamburg was first positioned as a pioneer Smart City - the state government of Hamburg decided on a "Mobility Program" which aimed to lay out a trajectory for transportation planning during the period 2014-2020 Hamburger Senat 2013. ${ }^{4}$ The mobility program starts with a review of the available forecasts

${ }^{4}$ In the three German city-states, the cabinet is called "Senate", and we report here that the strategy was adopted by the Hamburg Senate. 
regarding future needs of transportation of goods and passengers (ibid.11-17), covering the period to 2020, with some outlooks for 2050. It describes the administration's preferred scenarios regarding urban growth (ibid.:18-24) and discusses the current and future availability of financial resources (ibid.:27-29). Against the background of such expertise-based predictions, the program then lays out a number of activities that the administration intends to pursue or could consider pursuing, and defines the actors, procedural principles and sequential steps of transportation planning for Hamburg. Defining these procedures, at least in such a comprehensive form, is a non-obligatory activity of the administration, as is stated in the program (ibid.:61). Yet it reflects the 'state of the art' in transportation planning, as it has been, for example, also by the UN Habitat organisation's report on 'Planning and design for sustainable urban mobility: global report on human settlements 2013" (UN-Habitat 2013). Notably, this report praises the success of the French city of Nantes in integrating all mobility related decision-making authorities in one integrated body as a case of best practice (ibid.:176). Where the document promotes "Integrated urban land-use and mobility planning", again Nantes is named as a frontrunner "due to its long-term vision and commitment to an integrated approach to urban planning and transport over some 30 years" (ibid.:185). Furthermore, the programmatic report promotes "holistic and systemic thinking and action" that pays attention to the many ways in which urban mobility "is finely woven into the spatial, social, economic, political and environmental fabric of cities." (ibid.:198). While the UN Habitat organisation's earlier "Global Report on Human Settlements" (2009) was very explicit about the fact that urban planning and particularly "strategic spatial planning" is strongly dependent on "participatory processes and partnerships", the specific report on mobility rather stresses the importance of systematic and integrated thinking in a long-term perspective. Both programmatic documents, however, contrast sharply with an experimental approach to infrastructure development.

Concerning the procedural prescriptions, Hamburg's mobility program contains a sequential strategic planning process with periodical updating. Building on a guiding vision ("Leitbild") and a list of objectives, analyses are conducted, followed by pre-set methods, often including scenario building exercises, before fields of activity and measures are finally agreed upon (cf. Hamburger Senat 2013:60). For coordination between the multitude of administrative departments involved and the coordination of these with state-owned utilities and private providers of transportation services, as well as with the administration of hinterland areas, a specific advisory committee ("Mobilitätsbeirat") was established. The document announces that a simulation model of transportation needs and flows will be developed for long-term use, and that this development will be commissioned on the basis of a competitive tendering among invited specialists (ibid.:62). For the identification and prioritization of improvements in transportation infrastructures and mobility management activities, it lays out a multi-year schedule, emphasizing a clear sequence of phases that are each concluded by reaching a milestone: The identification of objectives and scenarios, through 2014 and 2015, was to be completed with a binding decision on the "framework of objectives" ("Zielrahmen"). A following phase of clarifications and decision making, through 2016 and 2017, was set to conclude with the adoption of an official "transportation development plan". The final phase of implementation, through 2017 to 2020, was envisaged to terminate with a last "implementation report" in 2020 (ibid.:63). 


\section{How do experimental approaches to transportation infrastructure impact on the potential for systemic transformations?}

Are the Smart City experiments addressing the conditions and requirements for transformative systemic change?

Despite a lot of emphasis on how "innovative" or even "revolutionary" actvities of $\mathrm{mSL}$ are, neither the proposal nor its implementation show ambitions to fundamentally challenge any existing institution of urban governance, or any entrenched way of providing mobility in the city (like e.g. the long-standing bias in favour of the 'automotive system' Urry 2008). There certainly is a commitment to achieving incremental improvements - especially in the form of increases in efficiency and liveability, but these are mostly constrained to micro-optimizations. While e.g. the provision of basic IT infrastructures of a certain type may ultimately change the ways in which cities are known and governed, the project $\mathrm{mSL}$ refrains from developing any clear strategy towards transformative systemic change. In line with the findings of Savini \& Bertolini (2019:842-3), the niche of Smart City related experiments in Hamburg seems also to follow the "trajectory of assimilation", where "transformative potential is co-opted by existent networks of actors aiming to legitimize an established institutional order" (ibid.) - at least as far as the mSL project is concerned.

\section{What are outcomes and impacts of the Smart City experiments in terms of transformative change?}

There is no evidence, that alternative approaches that could challenge the underlying problem of quantitative growth and resource consumption (e.g. rebound effects) have been tackled in mSL. The project seems to strengthen an attitude of ecological modernization rather than transformative social innovation, e.g. by providing proof of concepts for the technological innovations that it tests and promotes. Interestingly, however, despite the absence of serious ambitions towards transformative systemic change, some significant changes can be observed to what is considered appropriate urban governance processes.

Concerning planning routines, mainly the introduction of Urban Living Labs (ULL) as format of experimental governance challenges the existing planning regime. The approach provides a 'window of opportunity' for innovations and innovative actors: temporally for the duration of the project and territorially for the selected district of Bergedorf. Such a spatial exclusiveness, however, raises questions of how the selection process was organised and in how far the mechanisms and criteria were sufficiently transparent and legitimized.

Nevertheless, from an innovation point of view, ULLs might have the capacity to transform the planning system. This is even more the case, as Hamburg has experienced a number of comparable approaches in recent years, e.g. the International Building Exhibition IBA Wilhelmsburg which featured a specific planning regime that enabled innovative solutions beyond existing regulations, or HafenCity Hamburg where specific regulations, e.g. "Urban Areas" in zoning, have been invented and implemented to tackle the extremely complicated planning environment. 


\section{Underpinnings of an "experimental" versus an "integrated" approach to the shaping of transportation infrastructure}

The following section is dedicated to an exploration of conceptual models and values that underpin the Smart City related activities of the mSL project as compared to the pre-existing approach to integrated mobility planning in Hamburg. To contextualize this exploration, relevant actor constellations, the prevalent approach to participation and the democratic status of the experiments shall be described first.

\section{Actors, status, ambitions and dynamics of Smart City experiments in Hamburg}

The impulse for Hamburg's application to the Smart City call of the EU (H2020-SCC) was given by the Senate Chancellery's office for international cooperation against the background of the mayor's prioritization of the Smart City topic. The Hamburg consortium has been consisting of a triple helix partnership of public partners from the city and the district, partners from science and research, and private companies, e.g. MOIA, a daughter of Volkswagen AG, the public transport provider $\mathrm{VHH},{ }^{5}$ DeutscheTelekom AG as partner for digitalisation issues and Hamburg Energy, one of the local energy providers. This newly established consortium of public and private partners (as defined in the proposal from 2015) privileges a type of flexible and digitization-oriented staff both within the public administration and in "innovative" companies that collaborate in these projects. After all, a closed consortium was selected to benefit from the "lighthouse" project status and the connected funds, and to consequently shape the implementation of model (mobility) solutions in Hamburg-Bergedorf and beyond. The prescriptions of the EU-SCC calls (e.g. prioritizing public-private collaboration) matched well with a municipal state government, which since its inauguration strongly promoted public-private partnerships in order to mobilize both skills and capital from the private sector. The decision to include partners in the consortium was taken by social networks bridging the city state government with technology providers, researchers and consultants. In consequence, the actions now implemented as part of mSL have been selected on basis of the solutions potential partners promised to bring to the consortium and whether they were expected to increase the consortiums chances of winning the bid. Such considerations of the 'weight' a potential partner could bring to the consortium's bid naturally overruled a potentially critical assessment of the extent to which any such "solution" would actually solve perceived problems. ${ }^{6}$

The project aims at broad participation of citizens in the research and decisionmaking process which is organized by a private agency for urban planning and communicative processes at the neighbourhood level. The scope of the project was initially communicated in a rather diminished form: It was portrayed as an uncertain attempt to win EU funds for a set of experiments in a single district, which may, however, eventually earn the city the precious status of a "lighthouse city". At the same time, the proposal involved the shaping of partnerships and technological choices, that are likely to determine future infrastructural trajectories both in the ICT, energy and mobility

\footnotetext{
${ }^{5}$ Verkehrsbetriebe Hamburg-Holstein $\mathrm{GmbH}$

${ }^{6}$ As emerging consortia will most probably assess potential partners for the resources and recognition that they can bring to the consortium, hence improving the chances of the whole consortium, we assume that this selection process rather conserves existing power relations, due to its bias towards well established actors, while actors with deviating viewpoints are more unlikely to be selected.
} 
sectors and may preconfigure future decisions in the metropolitan area, e.g. via the establishment of development partnerships.

The formal status of the project is interestingly hybrid: Although the development of the bid to the H2020-SCC call was formally authorized by the city-state government and involved an officer of the district that was envisaged to become the site of experimentation, the negotiations on the emerging consortium had a very preliminary and informal status. Decisions, e.g. on how to eventually invest in transportation infrastructure - were made under the assumption that the chances of receiving the EU funding were quite small. Consequently, the negotiations were not made a subject of democratic deliberation and decision making e.g. in the districts parliament. The district parliament was informed about the project only after it had been started, that is after the district administration had already been commissioned by the Senate Chancellery with the realization of the project. In principal, the practicalities of bidding within such EU calls lead to frictions concerning the parliamentarian legitimation of the agenda setting that such applications necessarily contain, as they are usually developed under high time-pressure. Against this background, decisions about best ways to fulfil the content-related and procedural requirements of the calls are hence usually taken from a very pragmatic perspective.

The content of these decisions already reveal some of the normative underpinnings: the activities that the proposal prescribed for Hamburg and the two partner cities include mostly new technological developments in connection with refurbishments of buildings, usage of renewable energies, clean transport and supporting ICT solutions. As a core rationale, the mSL project aims at reducing the $\mathrm{CO}_{2}$ emissions of the participating cities, increasing the use of renewable energy sources and making the demonstration cities more environmentally friendly in general. By joining forces, the cities intend to deepen their understanding of technological solutions to common challenges such as smoothening traffic, improving city services and reducing $\mathrm{CO}_{2}$ emissions, and this knowledge is considered key to upgrading of infrastructures and the delivery of new services.

Moreover, the project's objectives go beyond the environmental dimension and also aim to create more inclusive cities that offer a high quality of life, where citizens play a vital role in the development of the city. In this regard, it is a further objective to develop the concept of "smart people". This ambition is specified in a project document: Peoples views shall be considered in decisions, "in order to ensure social acceptance" (mSL 2017). Yet, the consortium agreement with the EU on the funding details includes already what measures and technologies are to be implemented. Even the number of electric buses to be purchased and the number of public charging stations to be installed was contractually agreed upon, before there was any possibility of public participation. This factually constrains any future participation to relatively minor issues like the placing of charging stations. And the format of the public events, that have been conducted so far to ensure public participation, reflect this orientation towards "ensuring acceptance": they have predominantly been designed and announced as opportunities for getting informed and discussing about particular "smart" technologies, like e.g. smart grids or smart lampposts, rather than more openly discussing perceived problems and all possible solutions. 
Probably typical for a Smart City agenda (Söderström et al., 2014) mSL evidently narrowed the discussion, e.g. what sustainable mobility could look like in Hamburg, towards technological and high-tech solutions that correlate with strong economic interests of the automobile industry and ICT companies. Memorandums of Understanding with CISCO in 2014 and Daimler in 2017 underline this classical growth orientation which is affirmed by the strategy and actor constellation of the mSL project. Both are closely aligned with priorities of the EU calls and overarching economic agenda by mainly targeting technological solutions and efficiency increase and related stakeholder networks but do not reflect alternative and growth critical concepts like economic sufficiency or changes of life style.

In a nutshell, mSL involves the implementation of experiments as defined in a binding proposal on pilot sites together with European partner cities by members of a "triple helix" public-private EU H-2020 consortium. The Smart City experiments in the field of transportation specifically call for a shift away from planning for a slowly transforming mobility system towards the management of flows "in real-time" under the condition of ever faster technological change and connected uncertainties. Such "real time management" has indeed been used in several speeches of the lord mayor as a marker for heralding the innovative strength of Hamburg and for positioning the city as a primary "testfield" for emerging technology. Apparently, this ambition is shared across various departments of the city state administration, and in 2017 has also manifested itself in the (later successful) application to host the ITS world congress of 2021.

As can be seen in the following section, the activities of mSL clearly differ from the approach of integrated transportation planning particularly due to their experimental character, their spatial selectivity and their hybrid formal/informal status.

\section{Actors, status, ambitions and dynamics of integrated transportation planning in Hamburg}

In sharp contrast with the experimental approach of the Smart City activities, the mobility program of 2013 described a rational, territorial, sequential planning process (Hamburger Senat 2013). It is supposed to start with the identification of political objectives, on which coordinated steps towards the implementation of related infrastructural change would follow. It was developed by the local transport authorities and meant to be implemented in governance arrangements that had developed locally over many years. Transportation planning in Hamburg is hence seen as an integrative process under the leadership of the responsible department and its senator.

The program also clearly reflects an ambition to make transportation planning a rational, continuous and transparent process, in which public authorities lead multistakeholder consultation processes in a predefined and systematic way. It pays tribute to a trend towards network governance, yet in a highly formalized way. A section on "transportation planning with whom" (ibid.:61f), for example, defines exactly which public authorities (across governance levels) and which external partners have to be involved in a continuous dialogue in order to ensure acceptance of the final decisions. Importantly, in each step, and particularly in the phase of articulating political objectives, this process is meant to be inviting political contestation. Debates are foreseen primarily within the mobility advisory board, in which "the relevant groups of society" 
are to be represented (ibid.:61). To a certain extent, however, the making transparent of "objectives, targets, scenarios and measures" also enables civil society organizations, which are not part of the advisory board, and even individual citizens, to voice concerns and preferences. The advisory board has met eleven times since its establishment in 2014. ${ }^{7}$ A set of objectives and target values was published in January 2017, but a comprehensive transport development plan, which was originally planned to be released by 2017, has not been adopted by the Senate, but is currently to be developed in a participatory process that was started in September 2019. ${ }^{8}$

\section{Discussion}

The project $\mathrm{mSL}$ is less than 4 years young and it is too early to finally assess its practical outcomes. Yet the case study shows that the mSL Smart City lighthouse activities in Hamburg represent an approach to shaping mobility infrastructure in Hamburg that significantly differs from the pre-existing approach to integrated mobility planning: While it is formally legitimized, its (pre-) determination of technological choices has never been exposed to democratic scrutiny. Rather, it creates spaces for experimentation and, explicitly, innovation around new socio-technical configurations, in which crucial decisions are taken exclusively and in-transparently by 'experts', the selection of which has never been publically justified, except for the fact that the consortium has been prioritized within a competition of the European H2020 program. Transmitting the priorities of a European Innovation Platform (EIP) on Smart Cities and Communities (SCC) into local plans and implementations, the consortium clearly narrowed the discussion, e.g. about what sustainable mobility could mean in Hamburg, towards technological and high-tech solutions that correlated with strong economic interests of the automobile industry and ICT companies. The existence and success of the project clearly benefits the involved partners, and significantly increases the influence of them on decisions in the city. Also within the organisations included, staff involved in the project benefits from the expectation of gains in reputation and power (cf. Blanes, this issue), as they visibly contribute to the recognition of the city as a primary site for innovation and technological progress (Späth \& Knieling 2018).

We found the European Smart Cities and Communities (SCC) calls and the prescriptions it entails to have shaped the debates about the future of mobility infrastructure in Hamburg. Besides a clear preference for experiments with innovations that are close to market readiness, these calls also prescribed particular forms in which to organize smart urban development: public-private cooperation is obligatory, for example, and in some way "smart citizens" have to be involved in the process. The vision of Smart City development hence does not only take the form of an alternative (technological) development pathway of urban planning, but also of a new and very particular approach to planning or, rather, to directly shaping urban infrastructures (Späth \& Knieling 2019).

In our case of mSL in Hamburg, the experimental character of the activities was actually key in realizing many of these potentials for influencing the ways in which mobility infrastructures are governed: The low prospects of gaining the funding in a fierce

\footnotetext{
${ }^{7}$ See www.hamburg.de/bwvi/mobilitaetsbeirat

${ }^{8}$ See www.hamburg.de/bwvi/verkehrsentwicklungsplanung/
} 
competition among city-bound consortia, for example, enabled its hybrid formal status and justified the circumvention of democratic scrutiny.

All this clearly shows the characteristics of experimental governance in the sense of Evans et al. (2016). With regard to the role of the municipality in this game of experimentation (Kronsell \& Mukhtar-Landgren 2018), it can be diagnosed that Hamburg's city state government, in a hybrid way, simultaneously plays the roles of promoter and partner. There is municipal leadership and an emphasis on the fact that the democratic government has a final word, while in fact decisions are made on basis of perceived technological expertise and on eye-level between representatives of governments and technology providers (Späth \& Knieling 2018, 2019). This practice could hence serve as an example that "competitions often lead to de-politization of decision making and (...) scientification of politics" as Benz has warned (2004: 9, own translation). We detected a fundamental shift in how planners approach the assessment of future needs in the city. From planning for a slowly transforming system, the focus has shifted towards the management of flows "in real-time" under the condition of ever faster technological change and connected uncertainties. Whereas in the recent past there was an incumbent system of planning on the basis of more or less agreed upon future scenarios, which could at least theoretically be opened up for the involvement of citizens, the experiments that are currently conducted under the flag of proactive and experimental digitization are accessible only to a few governmental and commercial actors. The future of mobility is now repeatedly framed as volatile technological responses to users' exploding expectations regarding inter-modal real-time information. Algorithm-based anticipation shapes not only individual Smart City experiments themselves, but, more importantly, de-legitimizes the conventional and partly participatory approaches to planning on the basis of politically agreed upon objectives.

The EU money channelled through Smart City calls in the Horizon 2020 framework program seems to deliberatively foster such re-framings of infrastructure planning and the respective roles of urban governments and other actors. These funds provide primary opportunities for both local governments and private actors to gain more influence in these processes (e.g. vis-a-vis parliaments and citizens). Whether EU money is involved or not, the focusing of financial and human resources on projects that fit with the "Smart City" or "proactive digitization and innovation strategy" may, under the given conditions of scarce resources, very likely result in a comparative weakening of low-tech or alternative ambitions, and in a down-playing of questions of sustainability and equal accessibility.

In recent years, the hype surrounding smart innovation has prompted municipalities to keep abreast of new developments and to future proof their administration and infrastructures. There seems to be an associated narrowing down of solutions and problem solving corridors. Driven by business actors and their respective interests, hightech solutions moved into the core of the discussion and often seem to be without alternative. This hegemonic dominance can be found clearly in mSL Hamburg, which largely followed the mainstream of technological innovation. According to our observations, the EU and its funding schemes hence play a strong role in mainstreaming a particularly technology-oriented development path. As long as transformative ambitions are as constricted as in the case of the mySMARTlife project, it is rather unlikely that such experiments radically transform urban systems materially. However, over time, 
experiments could accumulatively result in an essential shift of what governance approaches are considered normal. While it has taken decades to establish integrative and participatory planning approaches, people might get used to processes again which involve mainly experts, and in which government officials and staff of technology providers meet on eye-level in arenas completely inaccessible and in-transparent to the public. Not to close this section on such a pessimistic note, we also glimpsed the possibility that some government representatives involved in the project may fundamentally re-assess the governance structures in place and may even have be enabled - not least through the learning opportunities that the intra-city cooperation within mSL provided - to imagine ways in which more thoroughly democratic procedures of mobility planning could be achieved in the future.

\section{Conclusion}

Like Smart City initiatives in many other places, the mySMARTlife project in Hamburg follows an experimental approach to the shaping of moblity infrastructure. It promotes the development of multiple experiments as a means to prepare public and private stakeholders jointly for the exploitation of opportunities that will arise from technological developments.

As a flipside of the emphasis that smart mobility initiatives commonly place on collaborative experimentation, they devalue other views on how an appropriate development of transportation infrastructure may be determined. We detected such a shift in the context of Hamburg by contrasting the attitudes towards anticipating urban mobility futures in two contemporary frameworks of transportation planning: the mobility program of 2013 and the mySMARTlife project. What we have found in Hamburg is not so much "Frankenstein urbanism", where the ideal of the Smart City is feared to result in "the forced union of different, incompatible elements" (Cugurullo 2018:73). Rather, we share the concerns of Cowley and Caprotti that "the experimental qualities of the smart city $[\ldots]$ issue a challenge to the very ambition of 'planning' the urban future" (2018:14).

It was insightful to pay attention to what extend actors were included in the context of these frameworks, and which groups gained and which lost influence. A challenge seems to be that the engagement of business actors - who are naturally interested in the development of markets for their solutions and hence place a strong emphasis on opportunities rather than challenges - holds the risk that necessary public debates about objectives and acceptable and unacceptable risks are prevented by public-private alliances or largely biased in favour of high-tech solutions. Thus, it seems very worthwhile to explore more deeply the in- and exclusiveness of the actor constellations in such processes, e.g. regarding the role of coincidences or strategies behind the selection of partners, and including a possible gate-keeper function of the process initiator. Of relevance are also a dynamic perspective and the consideration of scope for reflexivity, as well as impacts on policy making and technology transfer.

As planning literature has firmly established after decades of debate, a purely expertdriven process can hardly produce outcomes that sufficiently reflect local residents' ideas of appropriate and sustainable changes to urban infrastructures. For this reason, candidate solutions for future mobility demands should be exposed to societal deliberation at an earlier stage in their development. The literature on (constructive) 
technology assessment contains ample debates on how such an 'upstream' engagement could be achieved through public participation and dialogue, and what typical challenges, dilemmas and limitations of such an engagement are.

Our exploration of interplays between such an experimental approach to the shaping of infrastructures and a pre-existing approach to integrated planning has been a very modest first step towards the exploration of Smart City activities' "concrete effects on incumbent local practices of urban planning" that Cowley \& Caprotti have asked for (2018:15). Before solid conclusions and generalizations can be achieved, more empirical research is certainly needed. We especially urge for work that focuses on implications of such experimental approaches on prospects for democratic decision-making and citizen participation.

\section{Abbreviations}

CO2: Carbondioxide; EU: European Union; H2020-SCC: Horizon 2020 Program of the EU, Smart Cities and Communities section; ibid: ibidem: In the same place; ITS: Intelligent Transportation System; MLG: Multi-level Governance; MLP: Multi-level Perspective (within Transition Studies); mSL: mySMARTlife - a H2020-SCC project of the EU; ULL: Urban Living Lab

\section{Acknowledgements}

We thank the editor and two reviewers for helpful feedback on the original manuscript. Furthermore, we are very grateful for our interviewees sharing their views and information very generously and frankly with us.

\section{Authors' contributions}

PS has proposed to contribute to this article collection and developed the research design and the main argument. He also wrote most of the text. JK contributed with details on the mSL case study and thoroughly worked through the whole text several times. All authors read and approved the final manuscript.

\section{Funding}

Philipp Späth acknowledges to have received funding from Deutsche Forschungsgemeinschaft (DFG) in the context of an international consortium researching knowledge politics in smart urbanism under grant agreement No. FR 1514/6-1.

Jörg Knieling acknowledges to have received funding from the European Union's Horizon 2020 research and innovation programme, here the European Smart Cities and Communities (SCC) competitive calls, under grant agreement No. 731297 (mySMARTlife).

\section{Availability of data and materials}

An interview-guideline as used in the expert interviews is available on request. The transcripts of interviews cannot be made accessible due to confidentiality ensured to the interviewees.

\section{Competing interests}

The authors declare that they have no competing interests.

\section{Author details}

${ }^{1}$ Institute for Environmental Social Sciences and Geography, Albert-Ludwigs-University, Freiburg, Germany. ${ }^{2}$ Institute for Urban Planning and Regional Development, HafenCity University, Hamburg, Germany.

Received: 5 March 2019 Accepted: 31 December 2019

Published online: 31 January 2020

\section{References}

Benz A. Leistungswettbewerbe in der regionalen Raumentwicklungspolitik. DISP. 2004;157:4-10.

Bulkeley H, Castán Broto V. Government by experiment? Global cities and the governing of climate change. Trans Inst $\mathrm{Br}$ Geogr. 2012;38(3):361-75.

Cowley R, Caprotti F. Smart city as anti-planning in the UK. Environ Plann D Soc Space. 2018;37(3):428-48.

Cugurullo F. Exposing smart cities and eco-cities: Frankenstein urbanism and the sustainability challenges of the experimental city. Environ Plann A Econ Space. 2018;50(1):73-92.

de Jong M, Joss S, Schraven D, Zhan C, Weijnen M. Sustainable-smart-resilient-low carbon-eco-knowledge cities; making sense of a multitude of concepts promoting sustainable urbanization. J Cleaner Prod. 2015;109:25-38.

Evans J, Karvonen A, Raven R. The Experimental City. London and New York: Routledge by Taylor \& Francis; 2016.

Goldsmith S, Crawford S. The responsive city: engaging communities through data-smart governance, Wiley. 2014.

Joss S, Sengers F, Schraven D, Caprotti F, Dayot Y. The Smart City as global discourse: storylines and critical junctures across 27 cities. J Urban Technol. 2019;26(1):3-34.

Karvonen A, Cugurullo F, Caprotti F. Inside smart cities: place, politics and urban innovation. London: Routledge; 2019. Khor L. Human rights discourse in a global network: books beyond Borders, Routledge; 2016.

Kronsell A, Mukhtar-Landgren D. Experimental governance: the role of municipalities in urban living labs. Eur Plan Stud. 2018; 26(5):988-1007. 
Mora L, Bolici R, Deakin M. The First Two Decades of Smart-City Research: A Bibliometric Analysis. J Urban Technol. 2017;24(1 (3)): $1-25$.

Savini F, Bertolini L. Urban experimentation as a politics of niches. Environ Plann A Econ Space. 2019;51(4):831-48.

Senat H. Mobilitätsprogramm 2013 - Grundlage für eine kontinuierliche Verkehrsentwicklungsplanung in Hamburg. Hamburg: Senat der Stadt Hamburg; 2013.

Shelton T, Zook M, Wiig A. The'Actually Existing Smart City'. Camb J Regions Econ Soc. 2015;8:13-25.

Söderström O, Paasche T, Klauser F. Smart cities as corporate storytelling. City. 2014;18(3):307-20.

Spaeth P, Hawxwell T, John R, Li S, Löffler E, Riener V, Utkarsh S. Smart eco-cities in Germany: Trends and city profiles. Exeter University of Exeter (Smart-eco project); 2017.

Späth P, Knieling J. Endlich Smart-City-Leuchtturm: Auswirkungen des EU-Projektes mySMARTLife auf die Planungspraxis in Hamburg. Smart City - Digitale Technologien, Raumproduktion, Intervention. In: Bauriedl S, Strüver A, editors. Bielefeld, Transcript-Verlag; 2018. p. 345-56.

Späth P, Knieling J. In: Lösch A, Grunwald A, Meister M, Schulz-Schaeffer I, editors. Smart City Experimentation in Urban Mobility - Exploring the Politics of Futuring in Hamburg. Socio-Technical Futures Shaping the Present - Empirical examples and analytical challenges. Heidelberg: Springer VS; 2019. p. 161-85.

Townsend AM. Smart cities: big data, civic hackers, and the quest for a New Utopia. New York, W. W. Norton. 2013.

UN-Habitat. Planning sustainable cities: global report on human settlements. London: Routledge; 2009.

UN-Habitat. Planning and design for sustainable urban mobility: global report on human settlements 2013. Milton Park: Routledge; 2013.

Urry J. Governance, flows, and the end of the car system? Glob Environ Chang. 2008;18(3):343-9.

\section{Publisher's Note}

Springer Nature remains neutral with regard to jurisdictional claims in published maps and institutional affiliations.

\section{Ready to submit your research? Choose BMC and benefit from:}

- fast, convenient online submission

- thorough peer review by experienced researchers in your field

- rapid publication on acceptance

- support for research data, including large and complex data types

- gold Open Access which fosters wider collaboration and increased citations

- maximum visibility for your research: over $100 \mathrm{M}$ website views per year

At $\mathrm{BMC}$, research is always in progress. 